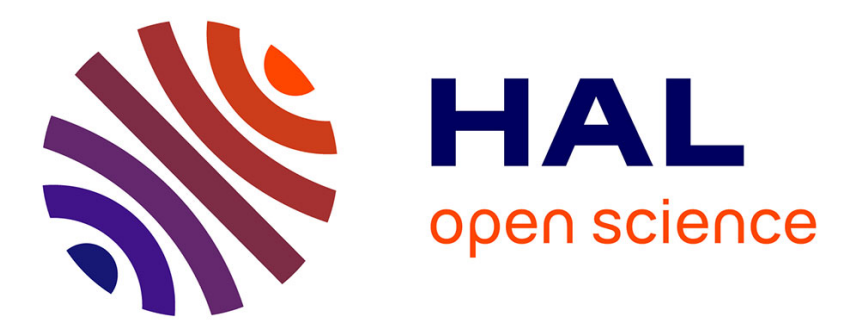

\title{
Sodium citrate ingestion and muscle performance in acute hypobaric hypoxia
}

Christophe Hausswirth, A-X Bigard, R. Lepers, M. Berthelot, C.-y Guezennec

\section{To cite this version:}

Christophe Hausswirth, A-X Bigard, R. Lepers, M. Berthelot, C.-y Guezennec. Sodium citrate ingestion and muscle performance in acute hypobaric hypoxia. European Journal of Applied Physiology, 1995, 71 (4), pp.362 - 368. hal-01781417

\section{HAL Id: hal-01781417 https: / hal-insep.archives-ouvertes.fr/hal-01781417}

Submitted on 30 Apr 2018

HAL is a multi-disciplinary open access archive for the deposit and dissemination of scientific research documents, whether they are published or not. The documents may come from teaching and research institutions in France or abroad, or from public or private research centers.
L'archive ouverte pluridisciplinaire HAL, est destinée au dépôt et à la diffusion de documents scientifiques de niveau recherche, publiés ou non, émanant des établissements d'enseignement et de recherche français ou étrangers, des laboratoires publics ou privés. 


\title{
Sodium citrate ingestion and muscle performance in acute hypobaric hypoxia
}

\author{
C. Hausswirth ; A-X. Bigard ; R. Lepers ; M. Berthelot ; C.-Y. Guezennec
}

Département de Physiologie Systémique, Centre d'Etudes et de Recherches de Médecine Aérospatiale, BP 73, F-91223 Brétigny sur Orge Cedex, France

\begin{abstract}
Eight subjects were studied on four occasions following ingestion of a 300-ml solution containing either sodium citrate $\left(\mathrm{C}, 0.4 \mathrm{~g} \bullet \mathrm{kg}^{-1}\right.$ body mass) or placebo (P, sodium chloride $0.045 \mathrm{~g} \bullet$ $\mathrm{kg}^{-1}$ body mass), at local barometric pressure $\left(\mathrm{N}, \mathrm{P}_{\mathrm{B}}\right.$ approximately $740 \mathrm{mmHg}, 98.7 \mathrm{kPa}$ ) or hypobaric hypoxia $\left(\mathrm{HH}, \mathrm{P}_{\mathrm{B}}=463 \mathrm{mmHg}, 61.7 \mathrm{kPa}\right)$. At $2 \mathrm{~h}$ after ingestion of the solution, the subjects performed prolonged isometric knee-extension at $35 \%$ of the maximal voluntary contraction (MVC) measured either in $\mathrm{N}$ or $\mathrm{HH}$. Results showed that ingestion of $\mathrm{C}$ led to an improvement in muscle endurance $(P<$ $0.01)$. However, this increase in endurance time for knee extensor muscles was only significant in $\mathrm{N}(+$ $22 \%, P<0.05$, compared to $+15 \%$, NS, at $\mathrm{N}$ and $\mathrm{HH}$, respectively). Following ingestion of sodium citrate, pre-exercise bicarbonate concentrations and $\mathrm{pH}$ levels were significantly higher than those measured after $\mathrm{P}$ ingestion. A significant treatment effect was observed for blood lactate concentrations with values higher for $\mathrm{C}$ than for $\mathrm{P}$ after 4,6 and $10 \mathrm{~min}$ of recovery $(P<0.05)$. Electromyographic signals (EMG) were obtained from the vastus lateralis muscle during the prolonged isometric contraction at 35\% MVC. The mean power frequency (MPF) significantly decreased in time under both N-P and N-C conditions. In HH, no significant decrease in MPF was observed with time. The results suggest that $\mathrm{C}$ ingestion was an ergogenic aid enhancing endurance during a sustained isometric contraction. In addition, it is suggested that fatigue during prolonged isometric contraction in $\mathrm{HH}$ was not directly related to factors determining the EMG signs of fatigue.
\end{abstract}

Key words Alkalising agent $\bullet$ Muscle fatigue $\bullet$ Myoelectric power spectrum Simulated high altitude

\section{Introduction}

It has been reported that prolonged activation of skeletal muscle leads to a decreased force-generating capacity (Vøllestad and Sejersted 1988). Muscle fatigue has been defined as a "failure to maintain the required or expected power output" (Edwards 1981) and it has been shown it can occur as a result of impairment of one or several links in the chain from the brain to the contractile proteins (Sahlin 1992). These potentiel sites of fatigue have allowed the determination of central or peripheral mechanisms (Fitts 1994). In the majority of cases, decline in muscle performance has been correlated with cellular mechanisms such as alterations in excitation-contraction coupling or cell metabolism.

Analysis of surface electromyographic (EMG) activity has been used increasingly to study muscle fatigue (De Luca 1984). It has been found that during a fatiguing submaximal contraction the power spectrum of the surface EMG shows a linear shift to lower frequencies (Petrovsky an Lind 1980; Zwarts et al. 1987; Arendt-Nielsen and Mills 1988). Moreover, an increase in EMG amplitude with time has been associated with prolonged submaximal muscle contractions (Arendt-Nielsen and Mills 1988). Although the mechanisms of these alterations have remained to date a matter of debate, changes in the myo-electric signals have been shown to provide information relating to events which occur inside the muscle (De Luca 1984).

Previous studies have shown that augmenting the body's bicarbonate buffering system through oral administration of sodium bicarbonate leads to an improvement in the performance of physical exercise lasting less than 7min (Jones et al. 1977; Sutton et al. 1981; Wilkes et al. 1983; Costill et al. 1984; Bouissou et al. 1988; Goldfinch et al. 1988). Muscle endurance has been reported to tend to be higher during metabolic alkalosis than during control conditions during either dynamic (Bouissou et al. 1989) or isometric contractions (Maughan et al. 1986). Moreover, a decline in the mean power frequency (MPF) of the power spectrum density, a factor known to accompany muscle fatigue, has been observed during exercise during metabolic alkalosis (Bouissou et al. 1989). However, several investigations have failed to show such an enhancement in performance (Kindermann et al. 1977; Katz et al. 1984; 
Kowalchuk et al. 1984; Wijnen et al. 1984; Lambert et al. 1993; Webster et al. 1993). The lack of consistency of the bicarbonate loading effects on performance may be explained in part by the low doses used in many studies, and to the gastro-intestinal disturbances linked to the usually high doses needed to improve exercise performance (McNaughton 1990). Sodium citrate is another buffering substance which has received some attention. It has been shown that the use of sodium citrate was effective in improving performance in exercise exceeding 120-s duration (McNaughton 1990; McNaughton and Cedaro. 1992). In contrast, other studies have failed to demonstrate such an improvement in anaerobic performance during dynamic exercise (Parry-Billings and MacLaren 1986; Kowalchuk et al. 1989; Ball and Maughan 1993). Although it is difficult to make a comparison between these studies, there is a lack of agreement among studies concerning the effectiveness of alkalising agents on exercise performance.

It has been previously shown that the respiratory alkalosis associated with acute exposure to high altitude increases the performance of exercise at the same relative intensity as that performed at sea level (McLellan et al. 1988). In addition, results of this investigation have demonstrated that the metabolic alkalosis resulting from the ingestion of sodium bicarbonate had no significant additional effect on exercise performance. However, the respective influences of hypobaric hypoxia $(\mathrm{HH})$ exposure and metabolic alkalosis on EMG parameters related to muscle fatigue remain, to our knowledge, to be determined.

The purpose of this study were

1. To clarify the effects of acid-base states altered by sodium citrate ingestion on isometric endurance capacity,

2. To verify the combined effects of respiratory and metabolic alkalosis on muscle performance at simulated high altitude, and

3. To determine EMG changes correlated with peripheral fatigue under altered acid-base states, and/or acute exposure to $\mathrm{HH}$.

\section{Methods}

Subjects

Eight healthy well-motivated male subjects (aged 25-35), volunteered to participate in this study after they were informed of the nature and possible inconveniences associated with the experiment. All the subjects gave their written informed consent. This experiment was approved by the local Ethics Committee before its initiation.

\section{Protocol}

The experiments were carried out on four occasions, at least 1 week apart. Prior to the first series of measurements, the subjects were familiarized with the test procedures. The subjects came to the laboratory at the beginning of the afternoon after eating a standard lunch, $2 \mathrm{~h}$ postabsorptive. After drawing a pretreatment sample of arterialized venous blood the subjects ingested $300 \mathrm{ml}$ of a flavoured drink containing either placebo $\left(\mathrm{P}, \mathrm{NaCl}\right.$ solution at a dose of $0.045 \mathrm{~g} \cdot \mathrm{kg}^{1}$ body mass) or tri-sodium citrate $\left(\mathrm{C}, \mathrm{Na}_{3} \mathrm{C}_{6} \mathrm{H}_{5} \mathrm{O}_{7} 2 \mathrm{H}_{2} \mathrm{O}\right.$ at a dose of $0.4 \mathrm{~g} \cdot \mathrm{kg}{ }^{1}$ body mass; alkalosis). The muscle test sessions were performed $2 \mathrm{~h}$ after ingestion of the liquid, either under local barometric pressure conditions $(\mathrm{N}$, PB approximately $740 \mathrm{mmHg}, 98.7 \mathrm{kPa}$ ) or in $\mathrm{HH}\left(\mathrm{P}_{\mathrm{B}}\right.$ approximately $\left.463 \mathrm{mmHg}, 61.7 \mathrm{kPa}\right)$. For $\mathrm{HH}$, the subjects sojourned in a hypobaric chamber for $90 \mathrm{~min}$ after ingestion of the liquid, and for up to 15 min of recovery after the muscle tests. Treatments were administered in double-blind fashion, and the order in which the experimental conditions were presented was randomized. Each subject exercised four times during $\mathrm{N}$ after ingestion of either placebo (N-P) or sodium citrate (N-C), and during $\mathrm{HH}$ after ingestion of either placebo (HH-P) or sodium citrate (HH-C). 
Right isometric knee extensions were performed using an isokinetic dynamometer (Cybex II, Lumex Inc., N.Y., USA). The subjects were in a sitting position, securely strapped into the muscle-test chair. The seated posture met the following specifications: hip angle $100^{\circ}$, knee angle $80^{\circ}$. To maintain isometric contractions in the quadriceps muscle, the speed of the dynamometer was set at $0^{\circ} \cdot \mathrm{s}{ }^{1}$. During muscle tests, the subjects were given verbal support by the experimenter.

The EMG activity of the vastus lateralis muscle was recorded by means of bipolar surface electrodes (Ag- $\mathrm{AgCl}$ electrodes, $7 \mathrm{~mm}$ diameter, Beckman, Noisy le Grand, France). The skin was prepared by surface abrasion using a sand pacte, cleaned with 33\% ether, 33\% aceton, 33\% ethyl alcohol. The impedance was checked, and only values below $5 \mathrm{k} \Omega$ were accepted. The two electrodes were coated with electrode gel and fixed lengthwise over the motor point (approximately $20 \mathrm{~cm}$ above the knee) with an interelectrode distance of $20 \mathrm{~mm}$. The electrodes were also securely fixed to the skin by adhesive tape. A multichannel EMG amplifier equipped with adjustable gain and high pass filters was used to record EMG acitivity. An oscilloscope was used for continuous monitoring of signals from the muscle and the dynamometer. After amplification, the signal was recorded on a TEAC tape recorder type R71 (TEAC Corporation, Musashino Centre, Tokyo, Japan).

The experimental procedure comprised the following steps:

1. The subjects were asked to perform maximal isometric contractions of short duration (2-3 s) of the knee extensor muscles. The maximal force was measured, and the best performance after four trials was selected as maximal voluntary contraction (MVC). Approximately 2-3 min elapsed between each of the four trials.

2. Following sufficient recovery lasting between 15 and $17 \mathrm{~min}$, the subjects maintained a prolonged isometric contraction of the knee extensor muscles at $35 \% \mathrm{MVC}$ for as long as possible. The required force of contraction was shown by an oscilloscope placed in front of the subject. The endurance time for this submaximal muscle contraction was measured until the subject was unable to maintain the required tension.

\section{EMG analysis}

The power spectum density function of each recording was calculated by fast Fourier transformation. The analyser computed a mean spectrum by calculating the root mean square (rms) values of 16 spectra obtained from consecutive time windows of 0.5 -s duration. The resulting spectrum was defined by 1,024 points in amplitude and phase. The final result of this signal analysis was a number of EMG variables including the rms and the frequency of MPF. It was calculated according to the equation given by Kwatny et al. (1970).

\section{Blood sampling}

Arterialized blood samples were drawn from a superficial vein of a prewarmed forearm $\left(50^{\circ} \mathrm{C}\right)$, before, and $2 \mathrm{~h}$ after ingestion of liquid. Additional samples of arterialized blood were taken from an indwelling catheter at the end of the submaximal fatiguing contraction, and after 2, 4, 6, 10 and 15 min of recovery. A 100111 sample of blood was immediately placed into a heparinized capillary tube and analysed in a blood gas analyser (Tacussel ABL 330, Radiometer, Copenhagen) for blood pH, partial pressure of carbondioxide, and partial pressure of oxygen. Values for blood bicarbonate concentration $\left(\left[\mathrm{HCO}_{3}\right]\right)$ were calculated from the Henderson-Hasselbach equation. A 1-ml sample of blood was deproteinized in 0.4 mol. perchloric acid before being centrifuged, and the supernant was frozen for later analysis for blood lactate. Blood lactate concentration $\left(\left[\mathrm{la}^{-}\right]_{\mathrm{b}}\right)$ was assayed in duplicate enzymatically, using a commercially available kit (MPR3 Lactate Boehringer Mannheim Germany).

\section{Statistics}

A two-way analysis of variance was used to determine the specific effects of sodium citrate ingestion (alkalosis) and high altitude exposure on blood $\mathrm{pH},\left[\mathrm{HCO}_{3}\right]$, [la- $]_{\mathrm{b}}$ and skeletal muscle performance. When a significant alkalosis by HH interaction was present a Student-Newman-Keuls post-hoc test was 
used to locate the differences. When there was no interaction, comparisons between groups were made using a student's t-test for paired samples. Statistical significance was accepted at $P<0.05$.

\section{Results}

Although the dose of $\mathrm{C}$ used was higher than in other investigations (Parry-Billings and MacLaren 1986; Kowalchuk et al. 1989), the subjects reported no problems of gastro intestinal distress after C ingestion, immediately after the isometric contraction, or during recovery.

Muscle performances

The changes recorded in both MVC and the mean endurance time of an isometric contraction corresponding to $35 \%$ MVC are reported in Table 1. The MVC remained unaffected by either metabolic alkalosis or HH. Metabolic alkalosis significantly improved muscle endurance $(P<0.01)$ without $\mathrm{HH}$ interaction. However, this increase in endurance time was only statistically significant at local PB $(+22.3 \%$ under $\mathrm{N}, P<0.05$, versus $+15.8 \%$ under HH condition, NS $)$.

\section{Blood parameters}

Figure $1 \mathrm{~A}$ illustrates the changes in $\left[\mathrm{HCO}_{3}\right]$. As expected, $2 \mathrm{~h}$ after the $\mathrm{C}$ ingestion, $\left[\mathrm{HCO}_{3}\right]$ was significantly higher in $\mathrm{C}$ groups than in $\mathrm{P}$ groups $(P<0.05)$. At the end of the prolonged isometric contraction of the knee extensor muscles, $\left[\mathrm{HCO}_{3}\right]$ remained higher during metabolic alkalosis than in the $P$ condition $(P<0.01)$. Similar findings were obtained during recovery. It was noted that $\left[\mathrm{HCO}_{3}\right]$ did not significantly decline during the $15 \mathrm{~min}$ of recovery. Acute $\mathrm{HH}$ did not affect the specific response of $\left[\mathrm{HCO}_{3}\right]$ to either $\mathrm{C}$ ingestion or muscle exercise.

A significant increase in blood $\mathrm{pH}$ was recorded $2 \mathrm{~h}$ after $\mathrm{C}$ ingestion during $\mathrm{N}(P<0.01)$ (Fig. 1B). Before exercise, blood $\mathrm{pH}$ was significantly higher in the HHP than in the N-P group $(P<0.01)$. A difference in blood $\mathrm{pH}$ between these two conditions remained significant during recovery $(P<0.01)$. Prolonged isometric knee extension did not significantly alter blood $\mathrm{pH}$ during $\mathrm{N}$. At the end of exercise, blood $\mathrm{pH}$ was higher in the HH-C than in the HH-P group $(P<0.01)$. Blood $\mathrm{pH}$ did not significantly decline during the 15 min of recovery either during $\mathrm{HH}$, or during alkalosis.

Prolonged isometric contraction of the knee extensor muscles did not increase [la -], above $3 \mathrm{mmol}$ $.1^{-1}$ (Fig. 2). After $4 \mathrm{~min}$ of recovery, the $\left[\mathrm{la}^{-}\right]_{\mathrm{b}}$ remained lower than $3.5 \mathrm{mmol}-\mathrm{-}^{-1}$, irrespective of the treatment. A slight overall increase in $\left[\mathrm{la}^{-}\right]_{\mathrm{b}}$ was observed after 4, 6 and $10 \mathrm{~min}$ of recovery in the subjects treated with $\mathrm{C}(P<0.05)$. Acute $\mathrm{HH}$ did not affect $\left[\mathrm{la}^{-}\right]_{\mathrm{b}}$.

\section{Analysis of EMG}

During sustained contraction, a continuous decline in MPF occurred in subjects of N-P and N-C groups (Fig. 3A). During HH, no significant decrease in MPF was observed with time either during alkalosis or after $P$ ingestion (Fig. 3B). A progressive increase in signal amplitude was recorded with time both during alkalosis and in control conditions in the N situation (Fig. 4A). During HH, the progressive increase in rms, measured under the two different acid-base conditions, was significantly lower than that recorded in N (Fig. 4B).

\section{Discussion}

Results of the present study indicated that the administration of $\mathrm{C}$ prior to sustained isometric contraction improves muscle endurance at local PB $(\mathrm{N})$. In spite of some controversial data, many previous studies have reported an increase in anaerobic exercise performance following induced metabolic alkalosis (Jones et al 1977; Wilkes et al. 1983; Costill et al. 1984; Maughan et al. 1986; Goldfinch et al. 1988; Bouissou et al. 1988; McNaughton 1990; McNaughton and Cedaro 1992). One of these studies has emphasized the effects of sodium bicarbonate ingestion on the endurance time during prolonged isometric contractions (Maughan et al. 1986). Results of the present investigation 
demonstrate that $\mathrm{C}$ ingestion had effects similar to those of sodium bicarbonate on endurance capacity during submaximal static contractions. The $\mathrm{C}$ has previously been used as a buffering substance to improve performance in exercise of durations in excess of $120 \mathrm{~s} \mathrm{(McNaughton} \mathrm{1990;} \mathrm{McNaughton} \mathrm{and}$ Cedaro 1992). The administration of $\mathrm{C}$ at doses of $0.3 \mathrm{~g} \bullet \mathrm{kg}^{-1}$ body mass only has been shown to have only a small effect on performance during a series of Wingate tests (Parry-Billings and MacLaren 1986), and did not alter performance during high intensity cycle exercise (Bali and Maughan 1993). Thus, in the present study, the use of a high dose of $\mathrm{C}\left(0.4 \mathrm{~g} \cdot \mathrm{kg}^{-1}\right.$ body mass $)$ improved endurance during isometric contractions during $\mathrm{N}$, without causing gastro-intestinal disorders.

It has previously been shown that, similarly to other buffering substances, $\mathrm{C}$ increases the level of blood $\left[\mathrm{HCO}_{3}\right]$ (McNaughton 1990). Mainwood and Cechetto (1980) have demonstrated that an increased extracellular buffer concentration promotes an efflux of lactate and $\mathrm{H}+$ from the cell due to a favourable $\mathrm{pH}$ gradient. Thus, it has been hypothesized that an increased extracellular alkalosis may delay the onset of a critical intracellular acidosis by enhancing lactate transport through muscle cell membranes. Isometric contractions of the knee extensor muscles between 30 and $50 \% \mathrm{MVC}$ have been found to result in high muscle lactate concentrations immediately after exhausting exercise (Karlson et al. 1975). Lower (20\% MVC) and higher ( $80 \%$ MVC) levels of isometric contractions induced lower muscle lactate concentrations. Thus, although no direct measurements have been performed in the present study, it would be expected that high muscle lactate concentrations would be observed after prolonged isometric contraction. On the other hand, it has been shown that increases in both intramuscular pressure and mean arterial blood pressure in the knee-extensor muscles occur with tension development from 0 to $100 \%$ MVC (Sjøgaard et al. 1988). These measurements suggest that isometric contractions exceeding 50\% MVC are sufficient to occlude muscle blood flow. Under our experimental conditions, although a decrease in muscle blood flow would be expected, it could be suggested that it remained greater than zero (Sjøgaard et al. 1988). Thus, because blood flow was not entirely occluded, it is hypothesized that it contributed to the persistence of a bicarbonate gradient between intra- and extracellular compartments.

It has been shown that at tensions of about $30 \%$ to $60 \% \mathrm{MVC}$, the major source of energy is anaerobic glycolysis (Ahlborg et al. 1972). In contrast to what has been observed in acclimatized lowlanders, it has been shown that acute hypoxia had no effect on the maximal lactacid capacity (Ceretelli 1981). Moreover, it has been previously demonstrated that acute exposure to hypoxia did not alter muscle adenosine triphosphate, phosphocreatine, and glycogen stores (Knuttgen and Saltin 1973). These data are in agreement with the Jack of significant decrease in muscle endurance during HH tests (Table 1). However, because of the duration of the muscle exercise, and because muscle blood flow was not entirely occluded, it could be suggested that oxidative metabolism could make a contribution to the energy required to sustain isometric contractions. Although $\mathrm{HH}$ had no detrimental consequence on the muscle endurance capacity, it cannot be ruled out that the smaller effect of $\mathrm{C}$ ingestion at simulated altitude may have reflected a decrement in oxygen availability associated with simulated altitude. In addition, the reduced potential benefits of metabolic alkalosis in acute $\mathrm{HH}$ could be related to the smaller increase in both blood $\left[\mathrm{HCO}_{3}\right](+18.5 \%$ compared to $+5.8 \%$, during $\mathrm{N}$ and $\mathrm{HH}$, respectively) and blood $\mathrm{pH}$ ( +0.09 unit compared to +0.01 unit during $\mathrm{N}$ and $\mathrm{HH}$, respectively) measured before exercise.

To explain the shift of the surface EMG to the lower frequencies that occurs with fatigue, it is possible to identify central and peripheral factors. Among central factors, it has been postulated that increased synchronisation of motor units (Furness et al. 1977), and recruitment of additional motor units with different firing rate characteristics may explain in part the spectrum changes. On the other hand, it has been shown that the frequency shift is caused mostly by alterations in the waveform of the motor unit action potentials (De Luca 1984). These depend on the conduction velocity of muscle fibres which is affected by the diameter of the muscle fibres, the intramuscular $\mathrm{pH}$, and the concentration of $\mathrm{K}^{+}$in the interstitium of the working muscles. Bouissou et al. (1989) have found that the shift in EMG power spectrum of the vastus lateralis muscle observed during brief dynamic exercise was greater during alkalosis than in placebo conditions. One result of the present study suggested that regardless of the duration of the isometric contraction, exhaustion corresponded to a similar level of compression of the EMG spectrum both during control and alkalosis conditions. The reasons why a higher decline in MPF was not observed during alkalosis may be related either to the buffering substance used or to the 
type of exercise. In vitro experiments have demonstrated that citrate reduced the membrane potential for contraction threshold (Dulhunty 1988). Although such expected effects of citrate have not been assessed in the present study, one hypothesis may be that the effects of hydrogen ions on the membrane potential, and their consequences on the conduction velocity, may be offset by a decrease in contraction threshold induced by $\mathrm{C}$ administration. On the other hand, it cannot be ruled out that the type of exercise (i.e. supramaximal exercise compared to sustained isometric contraction) could contribute to explaining the differences observed between our results and those reported by Bouissou et al. (1989).

One interesting finding of the present study is that in well-motivated subjects, isometric contraction of the knee extensor muscles to exhaustion was not associated with a parallel compression of the EMG spectrum during $\mathrm{HH}$. This finding suggests that during $\mathrm{HH}$, the endurance capacity of the knee extensor muscles may be limited by factors not directly related to those determining the EMG signs of fatigue. The major potential sites of fatigue have been recently identified (Fitts 1994). Among the central mechanisms, a decrease in the central motor drive of skeletal muscles could help explain the lack of compression of the EMG spectrum. This assumption appears to be supported by the observation that during $\mathrm{HH}$, a reduced central drive may be implicated as a cause of fatigue during exhausting dynamic exercise in well-motivated subjects (Kayser et al. 1994). In the present experiment, this decrease in the excitatory drive of lower motor neurons during isometric contraction at altitude could be associated with the lower increase in rms than during $\mathrm{N}$. This only slight increase in rms could be related to an altered recruitment of additional motor units to maintain the required force.

In addition to this factor, if it is proved, other mechanisms could contribute to the Jack of compression of the EMG spectrum at exhaustion during HH. Numerous metabolic and electrolyte changes that occur with high-frequency fatigue (i.e. increased concentrations of $\mathrm{H}^{+}$and inorganic phosphate, accumulation of $\mathrm{K}^{+}$and depletion of $\mathrm{Na}+$ in the T tubules; Fitts 1994) are associated with the myo-electric signs of fatigue (De Luca 1984). It is very likely that the alterations in the central control of muscle activation alone cannot account for fatigue during $\mathrm{HH}$. Although not statistically significant, the slight increase in muscle endurance after citrate administration may be related to peripheral effects of alkalosis as discussed above. As a consequence of the hypothesis of an increased central fatigue during $\mathrm{HH}$, it is suggested that the effects of $\mathrm{C}$ ingestion on the metabolic changes that occur during sustained isometric contraction may be minimized.

In conclusion, the results of the present investigation suggest that $\mathrm{C}$ ingestion $\left(0.4 \mathrm{~g}^{-\mathrm{kg}^{-1}}\right.$ body mass) can produce a significant ergogenic effect on muscle endurance during prolonged isometric contraction. The alkalosis-induced improvement in muscle performance was observed in the main during N. Under normobaric conditions, the enhanced endurance capacity was not associated with a parallel increase in EMG signs of fatigue. One interesting finding of this study was that during $\mathrm{HH}$, isometric contraction was limited by factors not directly related to those determining the EMG signs of fatigue.

\section{References}

Ahlborg B, Bergstrom J, Ekelund LG, Guarnieri G, Harris RC, Hultman E, Nordesjo LO (1972) Muscle metabolism during isometric exercise performed at constant force. J Appl Physiol 33:224-228

Arendt-Nielsen L, Mills KR (1988) Muscle fibre conduction velocity, mean power frequency, mean EMG voltage and force during submaximal fatiguing contractions of human quadriceps. Eur J Appl Physiol 58:20-25

Ball D, Maughan RJ (1993) Diet manipulation, citrate ingestion and the metabolic response to intense exercise in man. J Physiol 467: 73P

Bouissou P, Defer G, Guezennec CY, Estrade PY, Serrurier B (1988) Metabolic and blood catecholamine responses to exercise during alkalosis. Med Sci Sports Exerc 20:228-232 
Bouissou P, Estrade PY, Goubel F, Guezennec CY, Serrurier B (1989) Surface EMG power spectrum and intramuscular $\mathrm{pH}$ in human vastus lateralis muscle during dynamic exercise. J Appl Physiol 67:12451249

Ceretelli P (1981) Energy metabolism during exercise at altitude. In: Di Prampero, Poortmans (eds) Physiological chemistry of exercise and training. Med Sport 13:175-190

Costill DL, Verstappen F, Kuipers H, Janssen E, Fink W (1984) Acid-base balance during repeated bouts of exercise: influence of $\mathrm{HCO}_{3}$. Int J Sports Med 5:228-231

De Luca C (1984) Myoelectrical manifestations of localized muscular fatigue in humans. CRC Crit Rev Biomed Eng 11:251-279

Dulhunty AF (1988) Internai citrate ions reduce the membrane potential for contraction threshold in mammalian skeletal muscle fibers. Biophys J 53:609-616

Edwards RHT (1981) Human muscle function and fatigue. In: Hu-man muscle fatigue: physiological mechanisms (Ciba Foundation Symposium 82). Pitman, London pp 1-18

Fitts RH (1994) Cellular mechanisms of muscle fatigue. Physiol Rev 74:49-94

Furness P, Jessop J, Lippold OJC (1977) Long lasting increases in the tremor of human hand muscles following brief, strong effort. J Physiol 265:821-831

Goldfinch J, McNaughton LR, Davies P (1988) Induced metabolic alkalosis and its effects on 400-m racing time. Eur J Appl Physiol 57:45-48

Jones NL, Sutton JR, Taylor R, Toews CJ (1977) Effect of pH on cardiorespiratory and metabolic responses to exercise. J Appl Physiol 43:959-964

Karlson J, Funderburk CF, Essen B, Lind AR (1975) Constituents of human muscle in isometric fatigue. J Appl Physiol 38:208-211

Katz A, Costill DL, King DS, Hargreaves M, Fink WJ (1984) Maximal exercise tolerance after induced alkalosis. Int J Sports Med 5:107-110

Kayser B, Narici M, Binzoni T, Grassi B, Cerretelli P (1994) Fatigue and exhaustion in chronic hypobaric hypoxia: influence of exercising muscle mass. J Appl Physiol 76:643-640

Kindermann W, Keul J, Huber G (1977) Physical exercise after induced alkalosis (bicarbonate and Trisbuffer) Eur J Appl Physiol 37:197-204

Knuttgen GH, Saltin B (1973) Oxygen uptake, muscle high energy phosphates and lactate in exercise under acute hypoxic conditions in man. Acta Physiol Scand 87:368-376

Kowalchuk JM, Heigenhauser GJF, Jones NL (1984) Effect of pH on metabolic and cardiorespiratory responses during progressive exercise. J Appl Physiol 57:1558-1563

Kowalchuk JM, Maltais SA, Yamaji K, Hughson RL (1989) The effect of citrate loading on exercise performance, acid-base balance and metabolism. Eur J Appl Physiol 58:858-864

Kwatny E, Thomas DH, Kwatny HG (1970) An application of signal processing techniques to the study of myoelectric signais. IEEE Trans Biomed Eng 17:303-312

Lambert CP, Greenhaff PL, Ball D, Maughan RJ (1993) Influence of sodium bicarbonate ingestion on 
plasma ammonia accumulation during incremental exercise in man. Eur J Appl Physiol 66:49-54

Mainwood GW, Cechetto D (1980) The effect of bicarbonate concentration on fatigue and recovery in isolated rat diaphragm. Can J Physiol Pharmacol 58:624-632

Maughan RJ, Leiper JB, Litchfield PE (1986) The effects of induced acidosis and alkalosis on isometric endurance capacity in man Exercise physiology. In: Dotson CO, Humphrey JH (eds) Current Selected Research, vol. 2. AMS Press pp 76-82

McLellan T, Jacobs I, Lewis W (1988) Acute altitude exposure and altered acid-base states. II. Effects on exercise performance and muscle and blood lactate. Eur J Appl Physiol 57:445-451

McNaughton LR (1990) Sodium citrate and anaerobic performance: implications of dosage. Eur J Appl Physiol 61:392-397

McNaughton LR, Cedaro R (1992) Sodium citrate ingestion and its effects on maximal anaerobic exercise of different durations. Eur J Appl Physiol 64:36-41

Parry-Billings M, MacLaren DPM (1986) The effect of sodium bicarbonate and sodium citrate ingestion on anaerobic power during intermittent exercise. Eur J Appl Physiol 55 : 524-529

Petrovsky JS, Lind AR (1980) Frequency analysis of the surface electromyogram during sustained isometric contractions. Eur J Appl Physiol 43:173-182

Sahlin K (1992) Metabolic aspects of fatigue in human skeletal muscle. In: Marconnet P, Komi PV, Saltin B, Sejersted OM (eds) Muscle fatigue mechanisms in exercise and training. Med Sport Sci 34:54-68

Sjøgaard G, Kiens B, Jorgensen K, Saltin B (1988) Intramuscular pressure, EMG and blood flow during low-level prolonged static contraction in man. Acta Physiol Scand 128:475-484

Sutton JR, Jones NL, Toews CJ (1981) Effect of pH on muscle glycolysis during exercise. Clin Sci 61:331-338

Vøllestad NK, Sejersted OM (1988) Biochemical correlates of fatigue. Eur J Appl Physiol 57:336-347

Webster MJ, Webster MN, Crawford RE, Gladden LB (1993) Effect of sodium bicarbonate ingestion on exhaustive resistance exercise performance. Med Sci Sports Exerc 25:960-965

Wilkes D, Glehill N, Smyth R (1983) Effect of acute induced metabolic alkalosis on $800 \mathrm{~m}$ racing time. Med Sci Sports Exerc 15:277-280

Wijnen S, Verstappen F, Kuipers $\mathrm{H}$ (1984) The influence of intravenous $\mathrm{NaHCO}_{3}$-administration on interval exercise: acid-base balance and endurance. Int J Sports Med 5:130-132

Zwarts MJ, Haenen HTM, van Weerden TW (1987) The relation between the average muscle fibre conduction velocity and EMG power spectra during isometric contraction, recovery and applied ischemia. Eur J Appl Physiol 56:212-216 
Table 1 Effects of acute hypobaric hypoxia and sodium citrate ingestion on the maximal voluntary isometric contraction of the knee extensor muscles $(M V C)$ and the mean endurance time during a prolonged isometric contraction at 35\% MVC. $N-P$ local barometric pressure, placebo ingestion, $N-C$ local barometric pressure, sodium citrate ingestion, $H H-P$ hypobaric-hypoxia, placebo ingestion, $H H-C$ hypobaric-hypoxia, sodium citrate ingestion

\begin{tabular}{|c|c|c|c|c|}
\hline \multirow[t]{2}{*}{ Group } & \multicolumn{2}{|c|}{$\operatorname{MVC}(\mathbf{N} \bullet \mathbf{m})$} & \multicolumn{2}{|c|}{ Endurance time (s) } \\
\hline & Mean & SD & Mean & SD \\
\hline N-P & 262 & 64 & 156 & 17 \\
\hline $\mathrm{N}-\mathrm{C}$ & 239 & 57 & $192^{\mathrm{a}}$ & 17 \\
\hline HH-P & 241 & 48 & 145 & 10 \\
\hline $\mathrm{HH}-\mathrm{C}$ & 237 & 61 & 168 & 15 \\
\hline \multicolumn{5}{|l|}{ ANOVA } \\
\hline Alkalosis & \multicolumn{2}{|c|}{ NS } & \multicolumn{2}{|c|}{$P<0.01$} \\
\hline Hypobaric hypoxia & \multicolumn{2}{|c|}{ NS } & \multicolumn{2}{|c|}{ NS } \\
\hline Interaction & \multicolumn{2}{|c|}{ NS } & \multicolumn{2}{|c|}{ NS } \\
\hline
\end{tabular}


Fig. 1 Changes in blood bicarbonate concentrations $(\mathrm{A})$ and in $\mathrm{pH}(\mathbf{B})$ at rest before treatment $(R)$, before prolonged static contraction (Pre), and during recovery (mean and SD). N-P Placebo ingestion and exercise during normoxia, $\mathrm{N}-\mathrm{C}$ sodium citrate ingestion and exercise during normoxia, $\mathrm{HH}-\mathrm{P}$ placebo ingestion and exercise during acute hypobaric hypoxia, $\mathrm{HH}-\mathrm{C}$ sodium citrate ingestion and exercise during acute hypobaric hypoxia. After treatment, blood $\left[\mathrm{HCO}_{3}{ }^{-}\right]$values for $\mathrm{N}-\mathrm{C}$ and $\mathrm{HH}-\mathrm{C}$ were significantly greater than for $N-P$ and $H H-P$, respectively. After treatment, blood $\mathrm{pH}$ values for $\mathrm{N}-\mathrm{C}$ were significantly greater than for $\mathrm{N}-\mathrm{P}$. During recovery up to 6th min, blood $\mathrm{pH}$ values for $\mathrm{HH}-\mathrm{C}$ were significantly greater than for $H H-P$
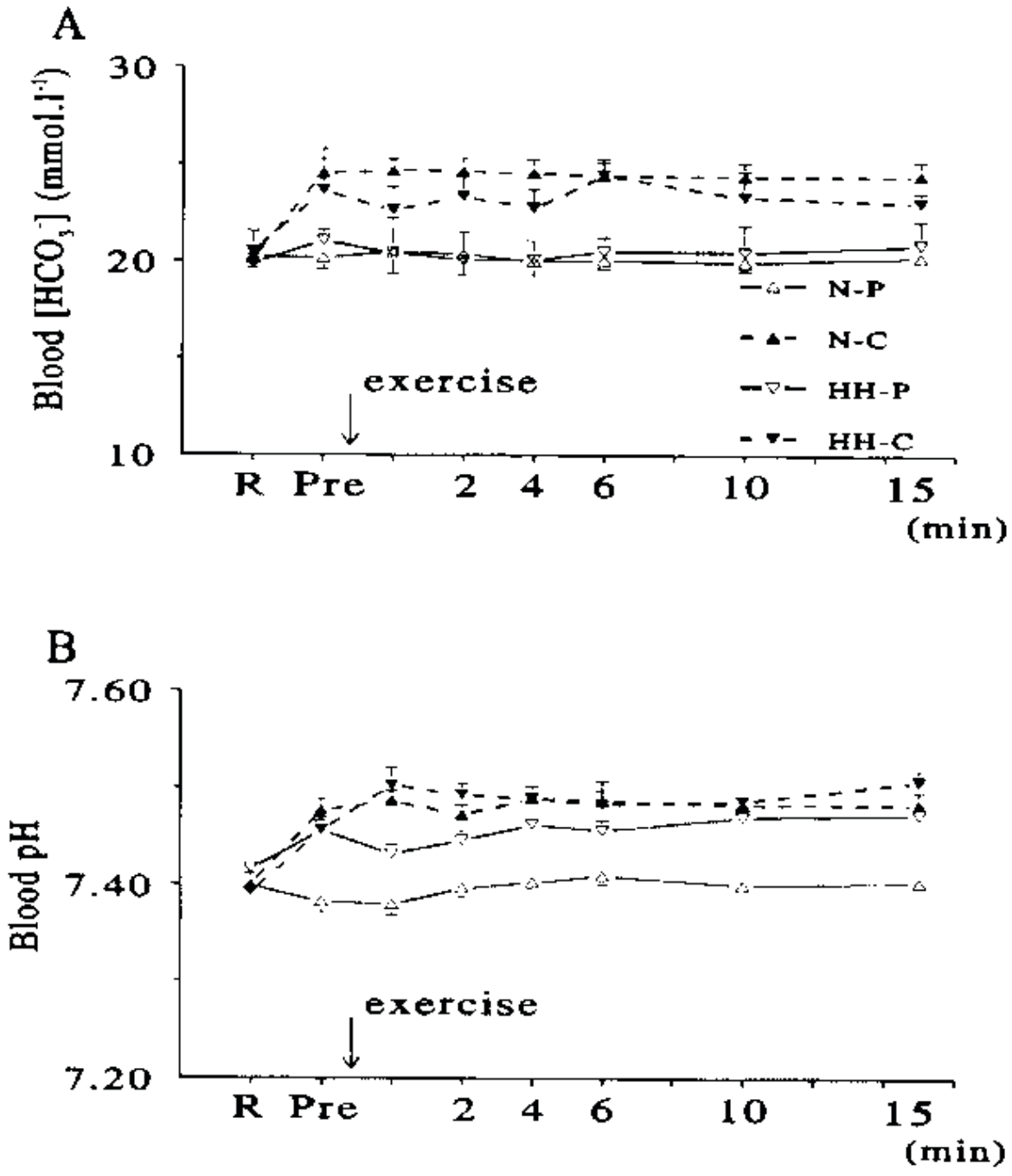
Fig. 2 Blood lactate concentrations before and during recovery from muscle exercise during the four experimental conditions (mean and SD). See Fig. 1 for definitions, etc.

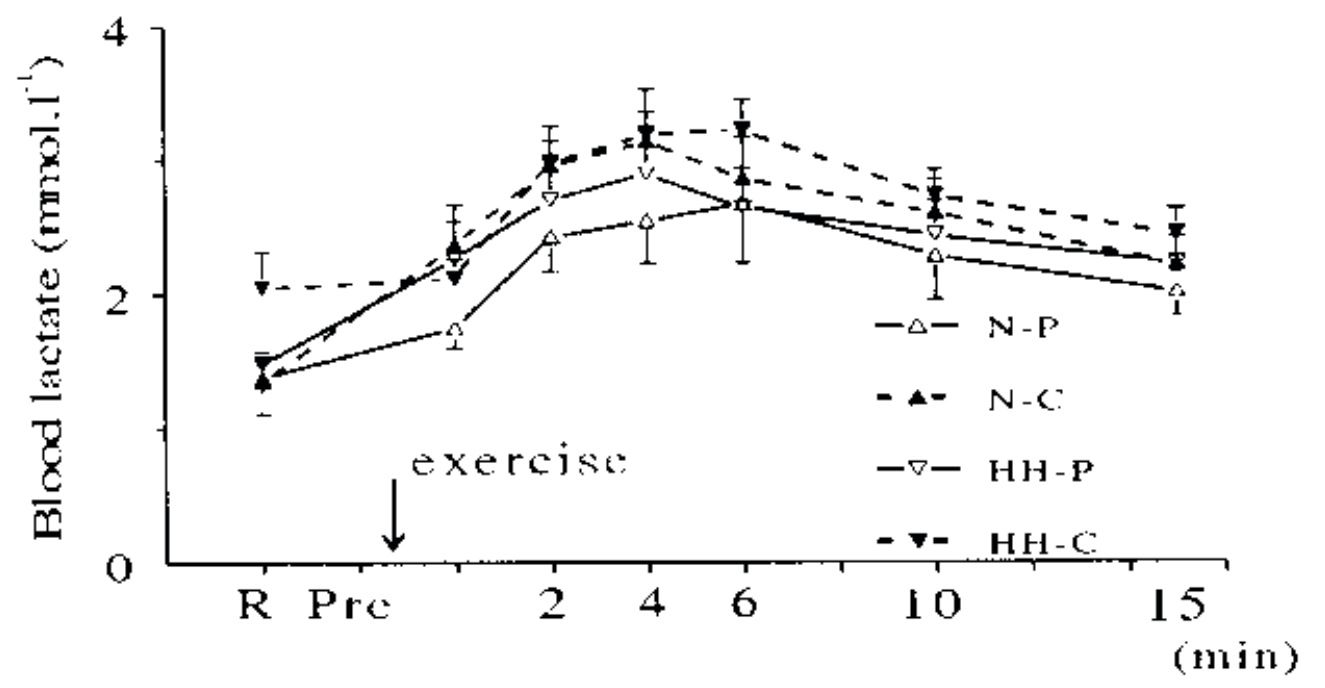


Fig. 3 Changes in mean power frequency $(M P F)$ during exercise in normoxia (A) and during acute hypobaric hypoxia (B) (mean and SD). At sea level, $M P F$ values measured from $20 \%$ endurance time were significantly lower than the mean value measured after $10 \%$ endurance time. See Fig. 1 for definitions, etc.
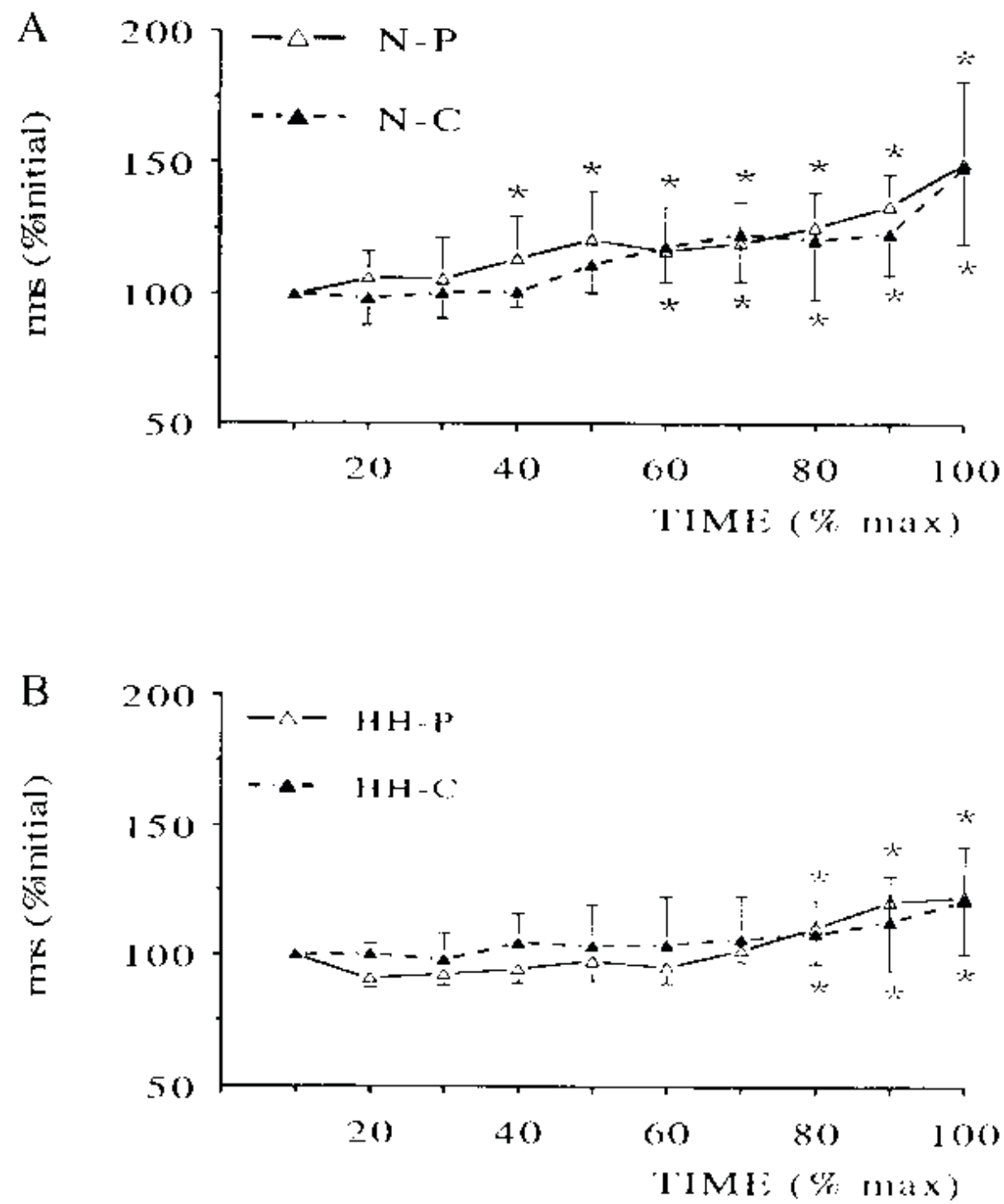
Fig. 4 Changes in signal amplitude (rms) expressed as percentages of initial values during muscle exercise at sea level (A) and hypobaric hypoxia (B) (mean and SD). * Significant difference from the initial value $(P<0.05)$. See Fig. 1 for definitions, etc.
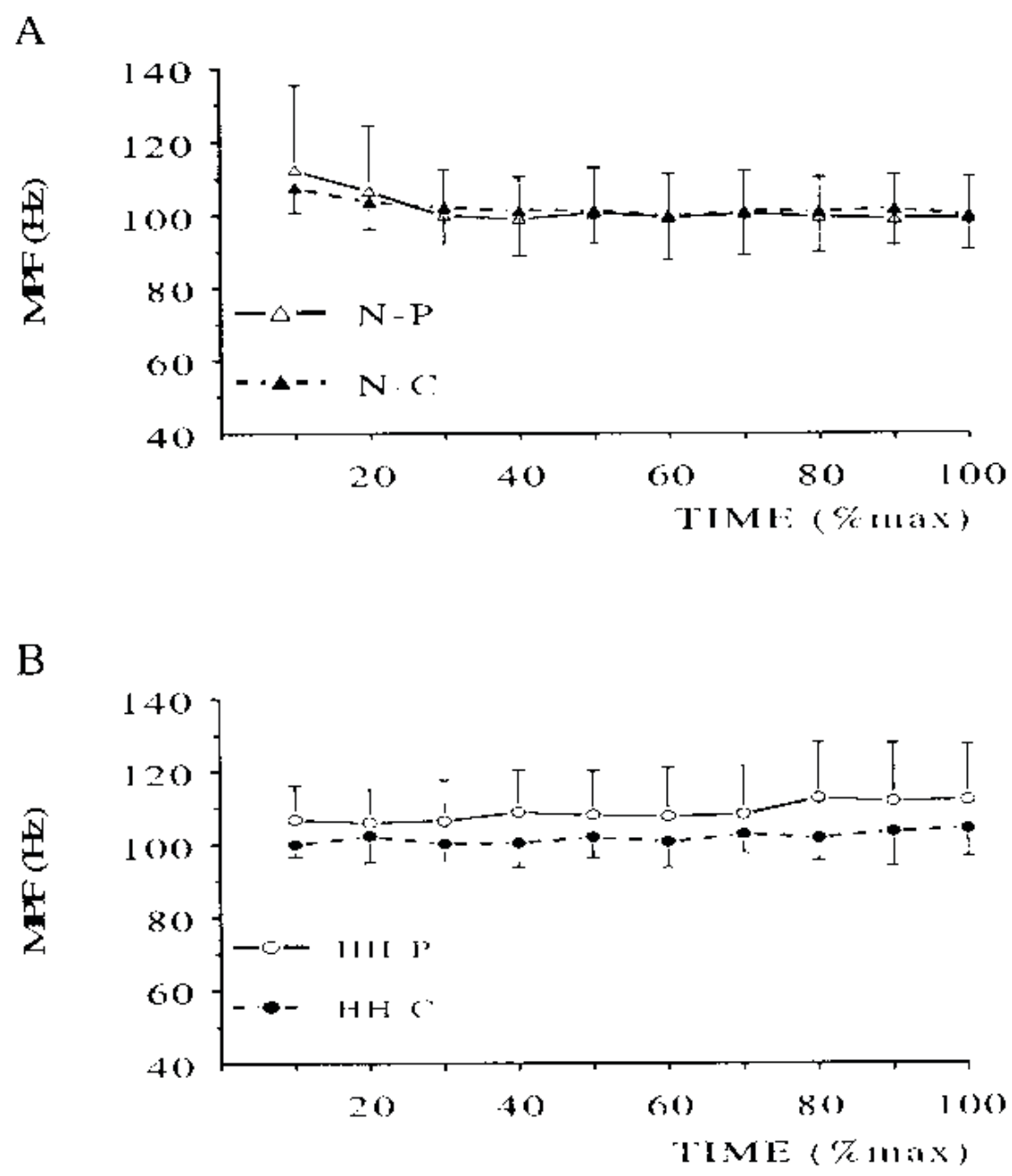